\title{
Lügner verraten sich doch nicht mit den Augen
}

\author{
Manche glauben es ganz genau zu \\ wissen: Wer lügt, der schaut nach \\ rechts oben; wer sich an die Wahrheit \\ hält, blickt eher nach links oben. \\ Alles Unsinn, sagen britische Forscher.
}

- Dass bestimmte Augenbewegungen ein Hinweis auf Lüge sind, wird sogar in Kommunikationsschulungen gelehrt Vertreter des sogenannten Neurolinguistischen Programmierens (NLP) behaupten, dass ein Mensch, der nach rechts oben blickt, lügt, während eine Person mit Blick nach links oben die Wahrheit sprechen soll.

Forscher in Schottland testeten 32 Probanden. Ein Teil der Versuchspersonen sollte lügen, während die anderen die Wahrheit sagen sollten. Die Videoauswertung der Interviews hinsichtlich kurzer und längerer Blicke nach links

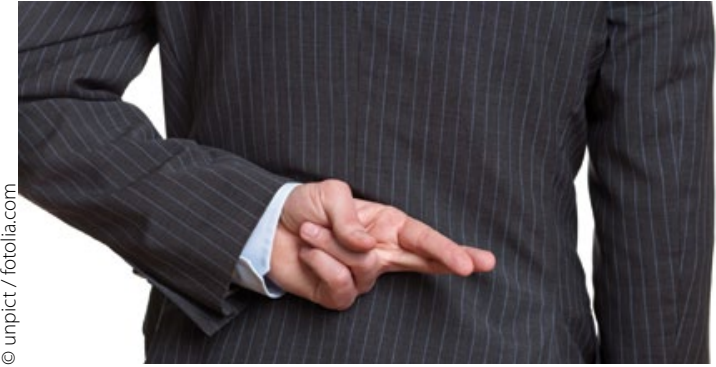

So leicht erkennt man Schwindler nur selten.

und rechts oben ließen keinen Zusammenhang zwischen Wahrheitsgehalt der Aussage und Blickrichtung erkennen

\section{Kommentar}

Die Augenbewegung hat zwar etwas mit geistiger Anstrengung zu tun, etwa dem Abrufen von Wissen oder dem Rekapitulieren einer Geschichte, sie ist aber nicht spezifisch für Lügen, so die Autoren. Da das Abrufen wahrer Sachverhalte eigentlich keine besondere geistige Aktivität erfordere, sei die Annahme entstanden, dass vor allem Lügner die Augen verdrehten. Und so geht die Suche nach verräterischen Signalen also weiter, mit denen sich Lügner unbewusst verraten sollen: Veränderung des Blutflusses im Gesicht, Ausrutscher im Schriftbild und so weiter. Ein Patentrezept, um Lügner sicher zu entlarven, muss wohl erst noch gefunden werden.

K. MALBERG =

\section{- C. Watt et al.}

(Dept Psychology, Edinburgh S33 7GS ; E-mail: Caroline Watt@e.ac.uk) The eyes don't have it: lie detection and neuro-linguistic programming. PLOS one July 2012,7 , 7, e40259

\section{Tödlicher Myokardinfarkt mit 5}
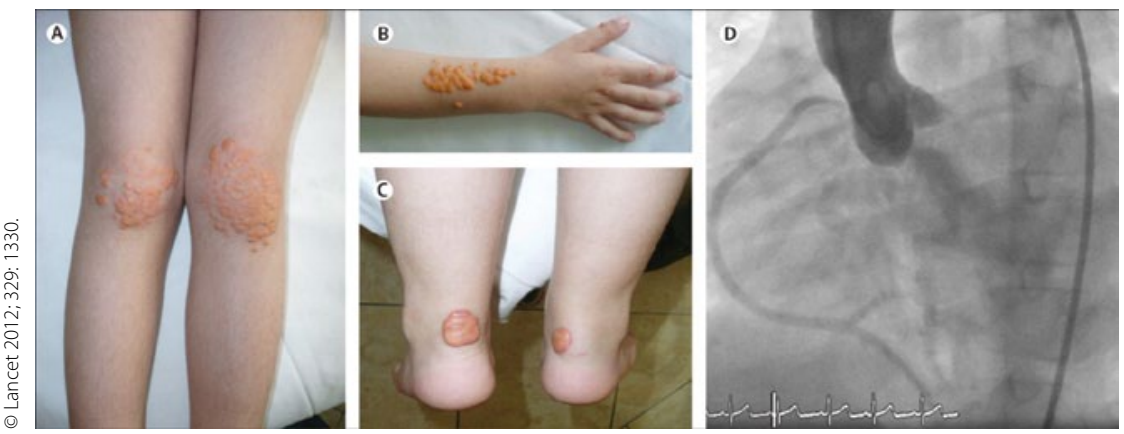

- Ein fünfjähriger Junge, bei dem im Alter von einem Jahr eine homozygote familiäre Hypercholesterinämie diagnostiziert worden war, wurde mit einem akuten ischämischen kardialen Ereignis in die Nothilfe eingeliefert. Er hatte Sehnenxanthome an den Handund Kniegelenken und an der Achillessehne (Abb. A, B, C). Trotz einer Be- handlung mit Cholestyramin war sein LDL-Cholesterin mit $1005 \mathrm{mg} / \mathrm{dl}$ extrem erhöht. In der Koronarangiografie erwies sich die linke Koronararterie als komplett, die rechte Koronararterie als teilweise verschlossen (Abb. D), sodass ein Stent implantiert werden musste. Nach dem Eingriff erfolgte eine LDLApherese über sieben Tage hinweg.
Trotz dieser Maßnahme verstarb der Junge drei Monate später am akuten Myokardinfarkt auf der Warteliste für eine kombinierte Herz-Lebertransplantation.

\section{Kommentar}

Die familiäre homozygote Hypercholesterinämie ist eine genetische Stoffwechselerkrankung mit verringerter Clearance des LDL-Cholesterins und frühzeitiger Entwicklung einer Atheromatose der Koronarien. Goldstandard der Behandlung ist die LDL-Apherese, bei der das LDL-Cholesterin selektiv aus der Zirkulation entfernt wird. Die familiäre Hypercholesterinämie diente als Modell für die Lipid-Hypothese der Atheromatose.

H. S. FÜESSL"

\section{- M. Macchiaiolo et al.}

(Korres.: marina.macchiaiolo@opbg.net): Homozygous familial hypercholesterolaemia. Lancet 2012; 329: 1330. 